\title{
Effect of aortic valve replacement on syncope in patients with aortic stenosis
}

\author{
Peter T Wilmshurst, Peter R Willicombe, Michael M Webb-Peploe
}

\begin{abstract}
Objective-To determine the role of exertion as a precipitating factor in syncope in patients with aortic stenosis. Design-Follow up for at least one year after aortic valve replacement.

Setting-Regional cardiac centre.

Patients-Consecutive patients who underwent aortic valve replacement for aortic stenosis and who had a history of syncope and no other clinically significant cardiac lesion were recruited during a five year period.
\end{abstract}

Methods-Patients were interviewed to determine the characteristics of syncope and were divided into those in whom syncope was consistently related to exertion (group 1, 26 patients) and those in whom it was not (group 2, 13 patients). Recurrence of syncope after valve replacement was determined at visits to the clinic.

Results-Groups 1 and 2 did not differ significantly with respect to valve area, age, or sex. In 13 of the 26 patients in group 1 syncope was preceded by angina despite the absence of coronary artery disease, but none of the 13 patients in group 2 had angina. After valve replacement none of group 1 and eight of the 13 patients in group 2 had recurrence of syncope (p $<0.01)$.

Conclusion-When patients with aortic stenosis experience syncope unrelated to exertion, the symptom is usually unrelated to the valve disease and another cause should be sought.

(Br Heart f 1993;70:542-543)

Aortic stenosis is the commonest valve lesion requiring surgery in most developed countries. Exertional syncope is a common presenting complaint in patients with this condition, ${ }^{1}$ although patients who have syncope without a clear relation to exertion are often found to have significant aortic stenosis. The aim of the present study was to determine whether non-exertional syncope is due to aortic stenosis or coincidental pathology, by assessing the nature of recurrent syncope after valve replacement.

\section{Patients and methods}

During a five year period every patient leaving this hospital after valve replacement for aortic stenosis was recruited to the study provided that there was a history of syncope, no other significant valve lesion (including haemodynamically important aortic regurgitation), no significant coronary disease (stenosis over $50 \%$ ), and no other cardiac abnormality. No patient had a history of cerebrovascular events or carotid bruits on examination but no routine investigations were performed to exclude such pathology.

Patients were divided into those with exertional syncope, which was defined as syncope only occurring when walking, running, or on strenuous effort (group 1), and those who had non-exertional syncope, which was defined as episodes of syncope some or all of which occurred without relation to these activities (group 2). A description of the events surrounding the syncope was obtained and recurrence of syncope was determined at follow up for at least one year. Although subjects were questioned about presyncope this was considered to be too subjective a symptom to justify analysis.

Statistical analysis of the data was by Fisher's exact test and Student $t$ test. A value of $p<0.05$ was considered significant. Results were expressed as means (SD).

\section{Results}

Of 459 patients who had aortic valve replacement, 39 fulfilled the recruitment criteria. Each replacement valve was a mechanical prosthesis and each patient had long-term anticoagulation with warfarin. There were no deaths in the first year after discharge in these 39.

In 26 patients syncope was always related to exertion (group 1) and in 13 of these syncope was preceded by angina despite the absence of coronary disease. In no patient in group 1 was there recurrence of syncope after valve replacement.

In 13 patients syncope was unrelated to exertion (group 2) and it was never preceded by angina. Eight of the 13 in group' 2 continued to have syncope after aortic valve replacement and this proportion was significantly different from group $1(p<0.01)$.

Four patients in group 2 had epilepsy. Before surgery, witnessed convulsions had been attributed to primary haemodynamic disturbance, but they continued after surgery and it became clear that there was no precipitating cardiac cause. They were eventually controlled in each case with anticonvulsants.

Four patients had syncope associated with 
tachycardia (one ventricular and three supraventricular) before valve replacement. The arrhythmias persisted in each after surgery but were only associated with syncope after valve replacement in the patient with ventricular tachycardia.

Two patients had postural syncope (on standing suddenly) before valve replacement and it recurred after surgery in one. In two patients syncope was preceded by nausea, a feeling of heat and faintness. Both patients were noted to become pale and sweaty during syncope. One had no further episodes after valve replacement. The other, who had a long history of fainting during pain and emotional stress, continued to faint after valve replacement. He has not been paced. In the last patient in group 2, occasional syncope occurred after valve replacement. No cause was found, but he declined extensive investigation and he has not had a tilt test.

The valve areas (determined with the Gorlin formula ${ }^{2}$ ) were similar in groups 1 and $2\left(0.52(0.20) v 0.59(0.22) \mathrm{cm}^{2}\right)$. The proportion of women in group $1(10 / 26)$ was similar to that in group $2(4 / 13)$. The age at the time of surgery in group 1 (mean 62, range 47 to 75 years) was the same as in group 2 (mean 62, range 51 to 71 years).

\section{Discussion}

Three mechanisms have been suggested to explain exertional syncope in patients with aortic stenosis ${ }^{1}$ : (a) cardiac arrhythmias, (b) sudden failure of an overloaded left ventricle during the stress of exercise, $(c)$ peripheral vasodilatation occurring suddenly and inappropriately in the face of fixed cardiac output. Exercise-induced cardiac arrhythmias usually follow and are secondary to an abrupt fall in blood pressure. ${ }^{3}$ Inappropriate vasodilation, the result of reflexes triggered by left ventric- ular baroreceptors ${ }^{4}$ and occurring during or just after exercise, is thought to be the mechanism in most cases. ${ }^{56}$

This study shows that syncope unrelated to exertion is a common finding in patients with aortic stenosis. In some cases the stenosed valve may act synergistically with other abnormalities (cardiac arrhythmia or abnormal vascular reactivity) to produce syncope. Thus replacement of the stenosed valve may mean that recurrence of the arrhythmia or vasovagal episode will no longer lead to syncope. In other cases where syncope is due to epilepsy, the epileptic focus may relate to cerebral emboli from calcium deposits on the stenosed aortic valve, explaining the relatively high incidence of epilepsy in this series. Such syncope will not be cured by valve replacement. This study shows that in most cases of non-exertional syncope, aortic valve replacement does not cure the syncope. Thus when a patient with aortic stenosis has non-exertional syncope, another cause (arrhythmias, epilepsy, orthostatic hypotension, vasovagal syndrome) should be sought.

We thank our colleagues in the department of cardiothoracic surgery for their help in this study.

1 Hall RJC. Aortic Stenosis. In: Julian DG, Camm AJ, Fox KM, Hall RJC, Poole-Wilson PA, eds. Diseases of the Heart London: Bailliere Tyndall, 1989:714

2 Carabello RA, Grossman W. Calculation of stenotic valve orifice area. In: Grossman W ed. Cardiac catheterization and angiography. Philadelphia: Lea and Febiger, 1986; 143-54.

3 Schwartz LS, Goldfischer J, Sprague GJ, Schwartz SP. Syncope and sudden death in aortic stenosis. $A m$ Cardiol 1969;23:647-58.

4 Johnson AM. Aortic stenosis, sudden death and the left ventricular baroreceptors. Br Heart f 1971;33:1-5.

5 Mark AL, Kioschos JM, Abboud FM, Heistad DD, Schmid PG. Abnormal vascular responses to exercise in patients with aortic stenosis. F Clin Invest 1973;52: patients $1138-46$.

6 Richards AM, Nicholls MG, Ikram H, Hamilton EJ, Richards RD. Syncope in aortic valvular stenosis. Lancet 1984;it:1113-6. 